\title{
Pentingnya Pemberian ASI Eksklusif untuk Mencegah Stunting pada Anak
}

\author{
${ }^{1}$ Suradi Efendi, ${ }^{2}$ Nour Sriyanah, ${ }^{3}$ Andi Suci Cahyani, ${ }^{4}$ Sri Hikma, ${ }^{5}$ Kiswati \\ 1,2,3,4,5 Prodi Ilmu Keperawatan, Sekolah Tinggi Ilmu Kesehatan Makassar \\ Korespondensi: atolnurse@gmail.com
}

\begin{abstract}
Abstrak: Stunting merupakan gangguan pertumbuhan linier yang tidak sesuai dengan umur. Salah satu faktor penyebab stunting yaitu tidak diberikannya ASI eksklusif pada Bayi. Prevelensi stunting Sebanyak 151.398 anak di Sulawesi Selatan menderita Stunting atau kondisi gagal tumbuh pada tahun 2020. Mereka tersebar pada lima kabupaten yang memiliki angka stunting tertinggi. Dari 24 kabupaten/kota di Sulsel, ada empat daerah dengan angka stunting tertinggi yakni di Kabupaten Bone 43 persen, Enrekang 39 persen, Jeneponto 36 persen, Takalar 34 persen, dan Bantaeng 33 persen. Dalam setahun terakhir memang terjadi pengurangan angka stunting antara 60007000 kasus. Sementara tahun lalu, Sulsel masih berada di 10 besar dengan angka stunting tertinggi secara nasional. Tujuan diharapkan peserta mampu mengetahui tentang pentingnya pemberian ASI Eksklusif untuk mencegah stunting pada anak. Metode dari pengabdian masyarakat adalah tahap perencanaan, pelaksanaan, monitoring dan evaluasi. Sasaran dari pelaksanaan pengabdian ini adalah ibu hamil sejumlah 9 orang. Pelaksanaan ini dibantu oleh berbagai pihak meliputi Kepala Kebidanan puskesmas Paccing, bidan posyandu dan mahasiswa untuk melaksanakan pengabdian masyarakat. Hasil dari pengabdian masyarakat menemukan bahwa ibu hamil akan mengaplikasikannya pada saat bayi lahir, mulai dari bayi berumur 0 sampai 6 bulan. Kesimpulannya adalah pengabdian masyarakat yang dilakukan berhasil untuk meningkatkan pemberian ASI Eksklusif untuk mencegah stunting pada anak di UPT Puskesmas Paccing Kab. Bone.

Kata Kunci: ASI Eksklusif, Stunting, Ibu hamil
\end{abstract}

\begin{abstract}
Stunting is a linear growth disorder that is not appropriate for age. One of the factors causing stunting is not giving exclusive breastfeeding to infants. Stunting prevalence A total of 151,398 children in South Sulawesi suffer from stunting or failure to thrive in 2020. They are spread over five districts with the highest stunting rates. Of the 24 regencies/cities in South Sulawesi, there are four regions with the highest stunting rates, namely in Bone Regency 43 percent, Enrekang 39 percent, Jeneponto 36 percent, Takalar 34 percent, and Bantaeng 33 percent. In the last year, there has been a reduction in the stunting rate of between 6000-7000 cases. Meanwhile, last year, South Sulawesi was still in the top 10 with the highest stunting rate nationally. The goal is that participants are expected to be able to know about the importance of exclusive breastfeeding to prevent stunting in children. The method of community service is the planning, implementation, monitoring and evaluation stages. The target of the implementation of this service is 9 pregnant women. This implementation is assisted by various parties including the Head of Midwifery at the Paccing Health Center, Posyandu midwives and students to carry out community service. The results of community service found that pregnant women will apply it when the baby is born, starting from babies aged 0 to 6 months. The conclusion is that the community service carried out was successful in increasing exclusive breastfeeding to prevent stunting in children at the UPT Puskesmas Paccing Kab. Bone.
\end{abstract}

Keywords: Exclusive breastfeeding, Stunting, Pregnant women

\section{PENDAHULUAN}

Kehamilan adalah pertumbuhan dan perkembangan janin intrauterine mulai sejak konsepsi dan berakhir sampai permulaan persalinan. Lamanya kehamilan mulai dari ovulasi sampai partus kira-kira 280 hari (40 minggu), dan tidak lebih dari 300 hari (43 minggu). Kehamilan 40 minggu ini disebut kehamilan matur (cukup bulan). Bila kehamilan lebih dari 43 minggu disebut kehamilan postmatur. Kehamilan antara 28 dan 36 minggu disebut kehamilan premature ${ }^{1}$.

Pertumbuhan merupakan indikator kesehatan anak, status gizi, dan latar belakang genetik. Pengukuran antropometri yang akurat dan berkelanjutan sangat penting untuk evaluasi klinik 
pertumbuhan anak, dan kecepatan pertumbuhan tinggi badan (TB) anak pada masa remaja, dapat dibandingkan tinggi badan anak dengan tinggi badan orang tuanya atau digunakan baku/ stantar tertentu yang di berlaku di populasi. Stunting adalah kondisi gagal tumbuh pada anak balita (bayi di bawah 5 tahun), akibat dari kekurangan gizi kronis sehingga anak terlalu pendek untuk usianya ${ }^{2}$.

Menurut World Health Organization (WHO) prevalensi balita pendek menjadi masalah kesehatan masyarakat jika prevalensinya $20 \%$ atau lebih. Menurut United Nations Children's Fund (UNICEF) tahun 2013 ada 165 juta (26\%) balita dengan stunting di seluruh dunia. Indonesia Prevelensi stunting Sebanyak 151.398 anak di Sulawesi Selatan menderita Stunting atau kondisi gagal tumbuh pada tahun 2020 berdasarkan prevelensi balita stunting Kabupaten Bone tahun 2017 mencapai 40,1 persen, kemudian tahun 2018 turun menjadi 37,3 persen, dan tahun 2019 turun menjadi 33,2 persen ${ }^{3}$. Stunting sudah menjadi masalah kesehatan masyarakat yang utama di Indonesia dibandingkan dengan masalah kesehatan lainnya. Kejadian stunting terjadi pada anak usia 0-59 bulan ${ }^{4}$.

Stunting tidak terjadi begitu saja, tetapi dimulai dari prakonsepsi ketika seorang remaja menjadi ibu yang kurang gizi dan anemia. Lebih parah lagi ketika ibu hamil dengan asupan gizi yang tidak memadai, terlebih lagi ketika ibu tinggal di lingkungan dengan sanitasi yang tidak memadai. Gangguan kesehatan dan perkembangan janin yang disebabkan oleh kurangnya asupan gizi (Fe, asam folat, hemoglobin) akan menyebabkan bayi lahir dengan berat badan rendah Kurangnya kehadiran ibu dalam pelayanan antenatak care selama kehamilan juga meningkatkan risiko berat badan lahir rendah pada bayi 5 .

Stunting dapat dicegah dengan beberapa hal seperti memberikan ASI Eksklusif, memberikan makanan yang bergizi sesuai kebutuhan tubuh, membiasakan perilaku hidup bersih, melakukan aktivitas fisik, untuk menyeimbangkan antara pengeluaran energi dan pemasukan zat gizi kedalam tubuh, dan memantau tumbuh kembang anak secara teratur. Pemberian ASI eksklusif menurut Organisasi Kesehatan Dunia World Health Organization (WHO) dan United Nations Children's Fund (UNICEF) merekomendasikan aturan menyusui adalah sebagai berikut: inisiasi menyusui dalam satu jam pertama setelah melahirkan, ASI eksklusif selama enam bulan pertama, dan terus menyusui selama dua tahun dengan makanan pendamping yang dimulai pada bulan keenam. ASI Eksklusif atau lebih tepatnya pemberian ASI

ASI Eksklusif adalah bayi hanya diberi ASI saja, tanpa tambahan cairan lainnya seperti susu formula, jeruk, madu, air teh, air putih dan tanpa tambahan bahan makanan padat seperti pisang, pepaya, bubur susu, biskuit dan bubur nasi ${ }^{6}$.

nutrisi optimal anak sehat pada usia ini, dianggap penting bahwa mereka diberikan ASI eksklusif selama 6 bulan pertama sebelum diberikan makanan pendamping. status gizi bayi usia 0-6 bulan dan status pemberian ASI (BF). Hal ini akan memudahkan pemahaman titik awal anak dalam hal status gizi sebelum pemberian makanan pendamping ASI dimulai ${ }^{7}$.

Menginjak usia 6 bulan ke atas, ASI sebagai sumber nutrisi sudah tidak mencukupi lagi kebutuhan gizi yang terus berkembang. Oleh karena itu perlu diberikan makanan pendamping ASI. Pemberian makanan pendamping ASI harus disesuaikan dengan perkembangan sistem alat pencernaan bayi, mulai dari makanan bertekstur cair, kental, semi padat hingga akhirnya makanan padat.

Faktor yang mempengaruhi terjadinya stunting pada anak balita yang berada di wilayah pedesaan dan perkotaan adalah pendidikan ibu, pendapatan keluarga,pengetahuan ibu mengenai gizi, pemberian ASI eksklusif, umur pemberian MP-ASI, tingkat kecukupan zink dan zat besi, riwayat penyakit infeksi serta faktor genetik. MPASI adalah singkatan dari Makanan Pendamping ASI, yang kita

This is an open-access article under the CC BY 4.0 International License

(c) Idea PengabdianMasyarakat (2021)

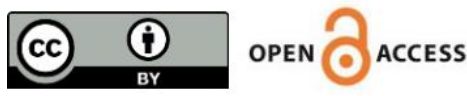


tahu bahwa makanan pendamping ASI diberikan kepada bayi tepa di usianya yang ke 6 bulan/180 hari. Dimana "menu utama" masih ASI hingga 1 tahun, menuju 2 tahun makanan lebih diutamakan daripada ASI untuk mencukupi izi harian si kecil. Tujuan dari MPASI adlah memperkenalkan makanan baru ke bayi selain ASI. Kenapa harus 6 bulan? Karena pencernaan anak sudah lebih siap menerima makanan padat, dan ASI sudah tidak mencukupi kebutuhan energi dan nutrisi si kecil. Bukan berarti ASI langsung lepas tetapi dibarengi dengan makanan padat ${ }^{8}$.

\section{METODE}

Metode dari pengabdian masyarakat adalah tahap perencanaan, pelaksanaan, monitoring dan evaluasi. Sasaran dari pelaksanaan pengabdian ini adalah ibu hamil sejumlah 9 orang. Pelaksanaan ini dibantu oleh berbagai pihak meliputi Kepala Kebidanan puskesmas Paccing, bidan posyandu dan mahasiswa untuk melaksanakan pengabdian masyarakat.

Pada bagian tahap persiapan mulai dari melakukan penjajakan ke UPT Puskesmas Paccing untuk menilai permasalahan dan pengabdian yang kita lakukan dapat berfungsi dengan baik. Setelah itu mulai melakukan pendekatan kepada kepala kebidanan dengan tempat yang akan digunakan untuk penyuluhan. Alat yang digunakan dalam penelitian ini adalah poster, leafleat dan kuesioner pemberian ASI Eksklusif. Pengisian kuesioner dilakukan oleh responden untuk mengetahui pengetahuan ibu hamil di desa Paccing Kab. Bone dengan didampingi oleh mahasiswa.

\section{HASIL DAN PEMBAHASAN}

Subyek penelitian ini adalah ibu hamil di wilayah kerja Puskesmas Paccing. Responden yang termaksud kriteria inklusi dan eksklusi sebanyak 9 responden. Penelitian ini menggunakan data primer dan diperoleh menggunakan lembar kuesioner yang diberikan kepada 9 responden. Lembar kuesioner yang berjumlah 9 diisi secara lengkap semua identitas dan pertanyaan oleh responden yaitu sebanyak 9 lembar kuesioner dengan demikian respon rate pengambilan lembar pengkajian sebanyak $100 \%$.

Tabel 1. Hubungan antara Pengetahuan ibu hamil tentang pemberian ASI Eksklusif dengan sikap ibu hamil untuk mencegah stunting pada anak.

\begin{tabular}{|c|c|c|c|c|c|c|c|}
\hline \multirow{3}{*}{ Pengetahuan } & \multicolumn{4}{|c|}{ Sikap } & \multirow{2}{*}{\multicolumn{2}{|c|}{ Jumlah }} & \multirow{3}{*}{$\rho$ Nilai } \\
\hline & \multicolumn{2}{|c|}{ Baik } & \multicolumn{2}{|c|}{ Kurang } & & & \\
\hline & $n$ & $\%$ & $n$ & $\%$ & $\mathrm{n}$ & $\%$ & \\
\hline Baik & 3 & 60 & 2 & 40 & 5 & 100 & 0,000 \\
\hline Sedang & 3 & 75 & 1 & 25 & 4 & 100 & \\
\hline Jumlah & 6 & 67 & 3 & 33 & 9 & 100 & \\
\hline
\end{tabular}

Sumber Data Tahun 2021

This is an open-access article under the CC BY 4.0 International License

(C) Idea PengabdianMasyarakat (2021)

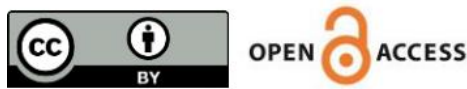


Pada tabel di atas diperoleh hasil bahwa dari 5 responden (100\%) yang memiliki Pengetahuan Baik dan Sikap baik sebanyak 3 orang (60,0\%), dan responden yang Sikap Kurang sebanyak 2 orang (40,0\%). Sedangkan dari 4 responden $(100,0 \%)$ yang memiliki Pengetahuan Sedang dan Sikap baik sebanyak 3 orang $(75,0 \%)$, dan responden yang Sikap Kurang sebanyak 3 orang $(33,3 \%)$.

Hal ini dapat di interprestasikan bahwa terdapat Hubungan antara Pengetahuan ibu hamil tentang pemberian ASI Eksklusif dengan sikap ibu hamil untuk mencegah stunting pada anak. Penyuluhan kepeda Ibu memang sangat penting, ini sejalan dengan penelitian Merdhika yang menemukan bahwa terdapat pengaruh penyuluhan mengenai sikap dan pengetahuan dalam meberikan ASI eksklusif ${ }^{9,10,11}$.
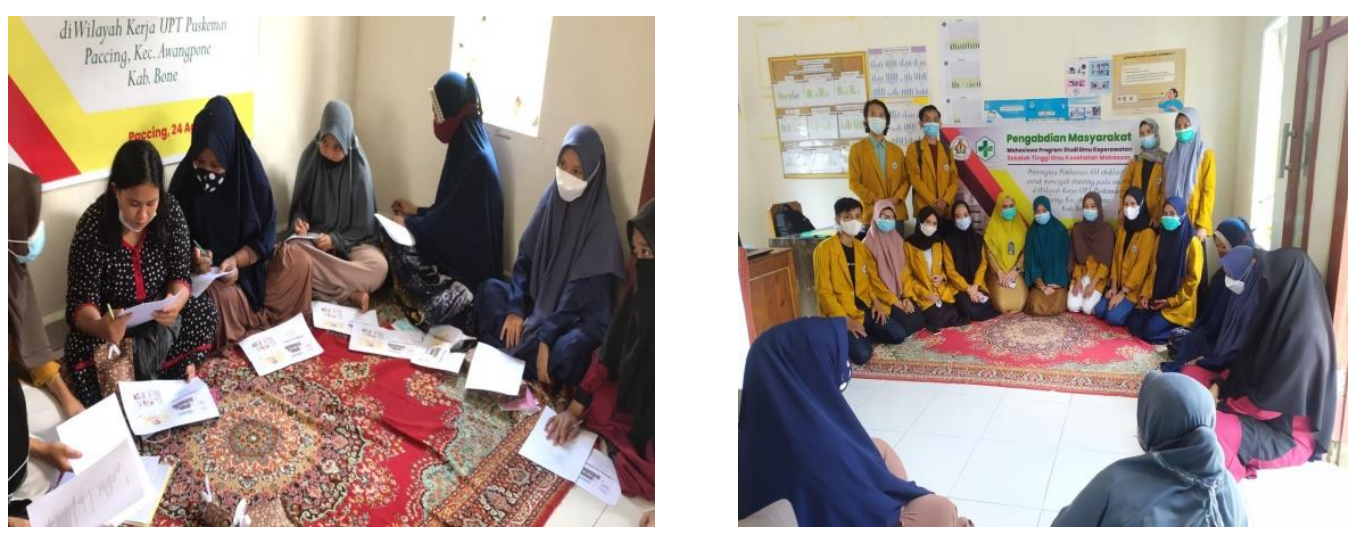

Gambar 1 dan 2 : Dokumentasi Kegiatan Pengabdian Masyarakat

Kegiatan ini sangat didukung oleh pihak Puskesmas selama melakukan pengabdian masyarakat ini tidak ditemukan kendala yang berarti. Sehingga proses pengabdian sampai di akhir terlaksana dengan baik sesuai dengan metode yang dilakukan. Beberapa pengabdian masyarakat yang dilakukan terkait dengan pencegahan stunting dan pemberian ASI Eksklusif pada anak. Subyek pengabdian ini bersama dengan masyarakat yang sedang memiliki jadwal posyandu dikalangan ibu hamil.

Pentingnya penyebaran informasi stunting dapat membantu untuk menurunkan kejadian stunting. Monitoring dan evaluasi dari kegiatan pencegahan stunting sangat penting untuk melihat perkembangan dan pertumbungan anak. Intervensi untuk menurunkan kejadian stunting sebenarnya dapat dimulai sejak dalam kandungan dapat diberikan pelayanan antenatal yang memadai sampai pada usia dua tahun. Pengukuran stunting dapat dilakukan dengan melakukan pengukuran panjang badan (PB) dan tinggi badan (TB) pengukuran ini kemudian dinilai berdasarkan dengan jenis kelamin.

1000 hari pertama kehidupan juga menjadi penentu untuk kehidupan selanjutnya sehingga menjadi hal yang penting untuk melakukan intervensi gizi berupa pemberian makanan tambahan, ASI eksklusif, asam folat, makronutrien dan mikronutrien lainnya

\section{KESIMPULAN}

Pengabdian masyarakat ini secara keseluruhan sangat efektif, sehingga diperoleh ada Hubungan antara Pengetahuan ibu hamil tentang pemberian ASI Eksklusif dan Hubungan antara sikap ibu hamil untuk mencegah stunting pada anak di UPT Puskesmas Paccing.

This is an open-access article under the CC BY 4.0 International License

(c) Idea PengabdianMasyarakat (2021)

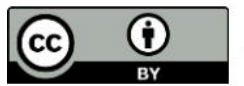

OPEN ACCESS 


\section{UCAPAN TERIMAKASIH}

Ucapan terimakasih kami ucapkan kepada Dosen pengampu mata kuliah Maternitas II dan Kepala Kebidanan UPT Puskesmas Paccing atas dukungan dalam pelaksanaan pengabdian masyarakat ini

\section{DAFTAR PUSTAKA}

1. Khairoh M. Asuhan Kebidanan Kehamilan. Surabaya:Cv.Jakad; 2019.

2. Mahmudah U. Modul Pelatihan Upaya Pencegahan Stunting Pada Balita Melalui Pendidik PAUD. Yogyakarta; 2020.

3. Kemenkes. Kinerja Organisasi Perangkat Daerah. Kementrian Kesehatan Republik Indonesia.

4. Fitriani $H$, Roswendi AS, Nurdiana P. The Risk Factors Of Exclusive Breastfeeding On Stunting Among Children Under Fivein One Of The City In Indonesia. 3rd Int Semin Glob Heal. 2019;3(1):186-189.

5. Oktavianingsih E, Fitroh SF. Developing Parenting Programs for Young Mothers as Preventive Stunting Efforts in Bangkalan, Madura. Proc 1st Int Conf Early Child Care Educ Parent (ICECCEP 2019). Published online 2019.

6. Karo MB. Perilaku Ibu Menyusui Dalam Pemberian ASI Eksk/usif. Jawa Barat; 2021.

7. Kuchenbecker J, Jordan I, Reinbott A, et al. Exclusive breastfeeding and its effect on growth of malawian infants: Results from a cross-sectional study. Paediatr Int Child Health. 2015;35(1):14-23. doi:10.1179/2046905514Y.0000000134

8. Zami. MPASI With Love. Jakarta Selatan; 2018.

9. Merdhika WAR, Mardji, Devi M. Pengaruh Penyuluhan ASI Eksklusif terhadap Pengetahuan Ibu tentang ASI Eksklusif dan Sikap Ibu Menyusui di Kecamatan Kanigoro Kabupaten Blitar. Teknol Dan Kejuru. 2014;37(1):65-72.

10. Nurkhayati A. Hubungan Antara Pengetahuan Ibu Tentang Asi Eksklusif Dengan Motivasi Pemberian Asi Eksklusif. Published online 2014.

11. Puspitasari A, Putra WD, Amir H. Pencegahan Stunting Pada Anak Di Desa Tamangapa Kec. Ma'rang Kab.Pangkep. Idea Pengabdi Masy. 2021;1(1):05-8. 